\title{
Catéter translumbar en vena cava inferior: última opción de acceso vascular para hemodialisis
}

Isabel Crehuet Rodríguez - Susana Mendinueta Saiz - Pilar Méndez Briso-Montiano - Ronte González. Palacios

Servicio de Nefrología. Hospital Universitario Río Hortega. Valladolid

\section{Introducción}

Los profesionales de enfermería nefrológica sabemos que el gran reto de las unidades de Hemodiálisis (HD) son los accesos vasculares. Según las guías de accesos vasculares en HD, realizadas por la SEN en colaboración con SEDEN y otros autores, la primera y mejor opción de acceso vascular es la fístula arteriovenosa interna (FAVI): nativa preferentemente, protésica, etc. Sin embargo, cuando estas posibilidades se agotan, se recurre a catéteres permanentes tunelizados cuya implantación se realiza en venas de gran calibre: yugular, subclavia, femoral, etc. En ocasiones, estos vasos, por determinadas patologías, dejan de ser eficaces para la HD, por lo que se hace necesario recurrir a una de las últimas alternativas (si no la última) de acceso vascular como es el catéter translumbar tunelizado en vena cava inferior.

Los objetivos que nos hemos planteado con este estudio, son los siguientes:

- Dar a conocer nuestra experiencia con los catéteres tunelizados en vena cava inferior.

\begin{tabular}{|c|}
\hline Correspondencia: \\
Isabel Crehuet Rodríguez \\
Servicio de Nefrología \\
Hospital Universitario Río Hortega \\
C/ Rondilla de Santa Teresa, 9 \\
47010 Valladolid \\
crebel@hotmail.com \\
\hline
\end{tabular}

- Confirmar que la vena cava inferior es un buen acceso vascular para conseguir una HD adecuada.

- Valorar si presenta mayor número de complicaciones que cualquier otro catéter permanente en otra vía.

- Demostrar que no implica mayores cargas de trabajo para enfermería.

- Comprobar que estos pacientes obtienen un grado de confort aceptable.

\section{Pacientes}

En nuestra unidad se dializan 38 pacientes, de los cuales 17 son portadores de catéteres permanentes. De entre estos 17, hemos estudiado los dos casos de catéteres permanentes colocados en vena cava inferior.

\section{Caso 1}

Varón de 58 años, con Enfermedad Renal Crónica (ERC) estadio $V$, por probable pielonefritis crónica, en programa de HD desde hace 11 años. La sesión de HD se realiza durante 4 horas, 3 veces por semana, con un dializador de AN69-ST.

\section{Aspectos a destacar de la historia clínica}

- Realización de 6 fístulas arteriovenosas internas, siendo la de mayor duración una FAVI húmeroaxilar izquierda con injerto de safena, funcionante durante 24 meses. 
- Colocación de catéter peritoneal e inclusión en programa de diálisis peritoneal (diálisis peritoneal continua ambulatoria y diálisis peritoneal automática), donde permanece durante 2 años con posterior retirada del catéter por peritonitis fúngica, por lo que ingresa de nuevo en programa de HD periódica.

- Colocación de varios catéteres permanentes y varios temporales siendo el de mayor duración un catéter permanente tunelizado, en vena yugular izquierda con una supervivencia de 5 meses.

- En agosto de 2005, tras comprobar el fracaso del catéter que portaba en ese momento, unido a un síndrome de la vena cava superior, se procede a la colocación de un nuevo catéter túnelizado tipo Perm-cath para hemodiálisis en vena cava inferior (figura 1).
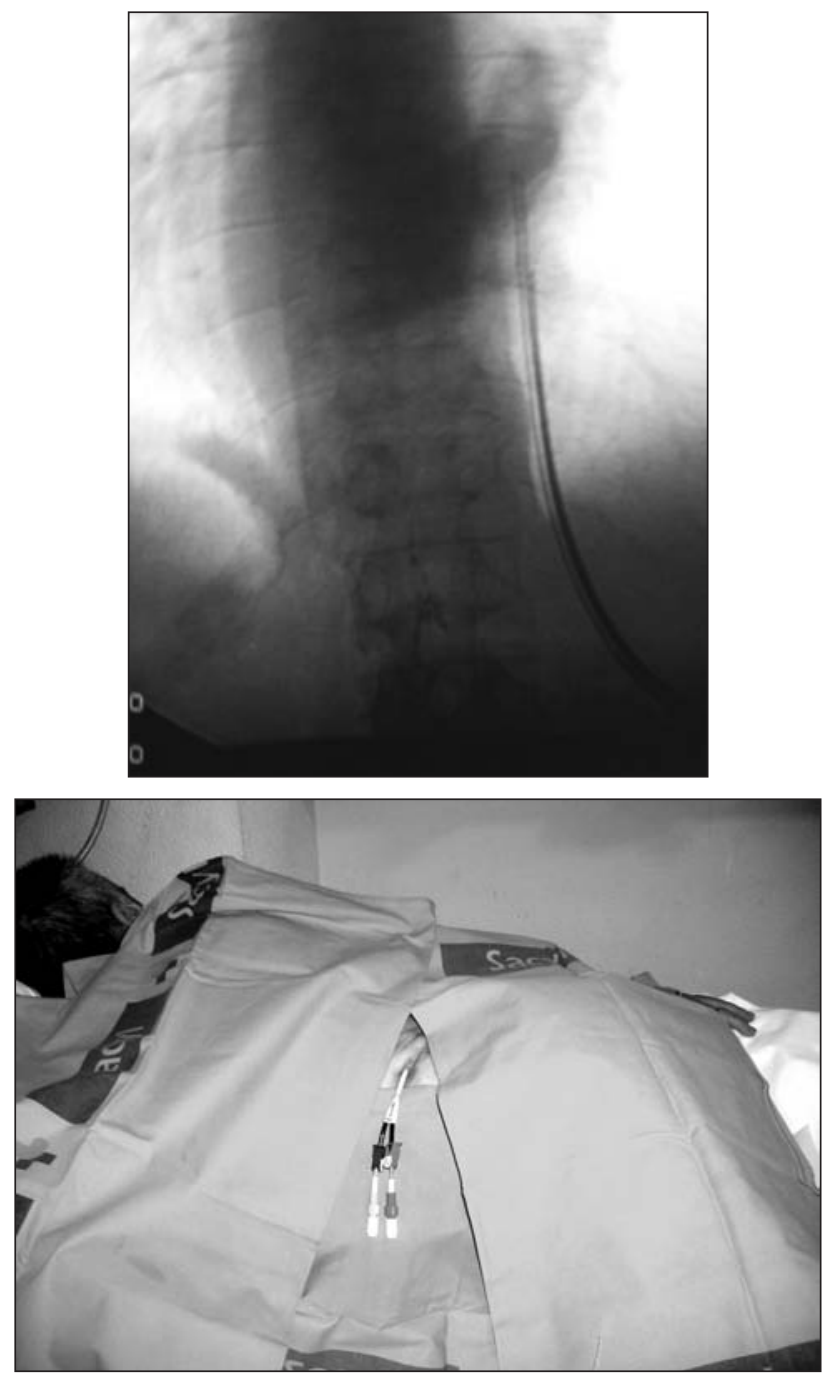

Figura 1: Paciente 1. Radiografía en proyección posteroanterior del catéter tipo Perm cath y parte externa del mismo.

\section{Caso 2}

Mujer de 81 años, con Enfermedad Renal Crónica (ERC) estadio $V$, de etiología no filiada, en programa de HD desde hace 7 años. La sesión de HD, se realiza durante 3 horas 30 minutos 3 veces por semana, con un dializador de AN69-ST.

\section{Aspectos a destacar de la historia clínica}

- Realización de 6 fístulas arteriovenosas no funcionantes, de las cuales la de mayor duración fue de 8 días.

- Colocación de 6 catéteres permanentes y varios temporales, siendo el de mayor duración un catéter permanente tipo Tesio en vena yugular derecha con una supervivencia de 35 meses.

- Finalmente, tras cuadro de fiebre, afectación general y disfunción del catéter que portaba entonces, se procede a su retirada, comprobándose trombosis de las venas yugulares y cava superior con importante circulación colateral, por lo que se decide la implantación de un catéter tunelizado tipo Tesio en vena cava inferior (figura 2).
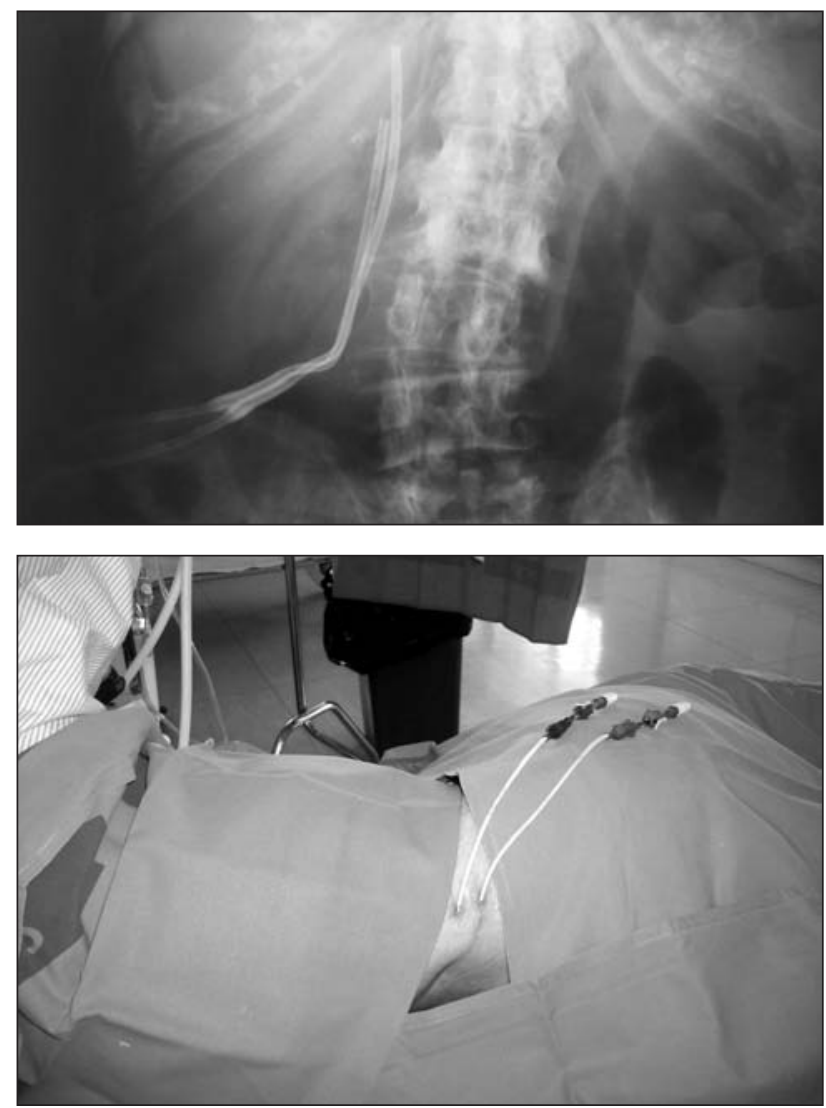

Figura 2: Paciente 2. Radiografía en proyección anteroposterior del catéter tipo Tesio y parte externa del mismo. 
El proceso de implantación de estos catéteres se realiza bajo sedación. Para ello se coloca al paciente en decúbito supino y se introduce, a través de vena femoral, una guía hasta llegar a vena cava inferior. A continuación, con el paciente en decúbito prono, se hace una punción percutánea en la zona derecha de la columna, a nivel de L4-L5 (dependiendo de la altura del sujeto), y bajo control radioscópico se llega con la aguja de punción hasta donde está la guía señal. Posteriormente, se procede como con cualquier otro catéter tunelizado. La mayor complicación posible durante este proceso es la hemorragia retroperitoneal.

Hemos hecho un estudio retrospectivo desde la implantación de ambos catéteres en agosto de 2005 (paciente $1^{\circ}$ ) y octubre de 2006 (paciente $2^{\mathrm{a}}$ ) hasta abril de 2007. La conexión a HD se realizó, según protocolo de la unidad, entre dos personas, extremando así las medidas de asepsia. Destacar que la desconexión puede realizarla una sola persona con las mismas medidas asépticas. El orificio de salida del catéter lo lavamos con una gasa empapada en suero salino y posteriormente lo secamos. Colocamos una gasa alrededor del primer tramo de salida del catéter para evitar el roce con la piel, aplastamientos y contacto del pegamento de los apósitos con el catéter; y ponemos un apósito cubriéndolo.

En la desconexión, sellamos el catéter con $1 \mathrm{ml}$ de suero salino al $0,9 \%$ más la cantidad de heparina al $5 \%$ necesaria hasta completar la luz de ambas ramas, lavamos los extremos con suero salino al 0,9\% y cerramos con los tapones. Finalmente introducimos las ramas en un apósito tipo "saco" que fijamos a piel para evitar traumatismos. Sujetamos todo esto con una faja abdominal con cierre de velcro en el paciente $n^{\circ} 1$. En la paciente $n^{\circ} 2$, lo hacemos con esparadrapo Mefix®.

Durante las sesiones de HD se estudiaron flujos de bomba arterial, Kt/v y presión venosa. También tuvimos en cuenta el número de infecciones, el estado del orificio de salida y la comodidad del paciente. Desde la implantación de estos catéteres se instauró tratamiento anticoagulante con dicumarínicos; el resto de pacientes portadores de catéteres en nuestra unidad, salvo que sea por otra causa, no se tratan con anticoagulantes orales.

\section{Resultados}

Se estudiaron un total de 234 sesiones de HD en el primer caso y 72 en el segundo obteniéndose los siguientes resultados:

- La media de los flujos de bomba fue de 350 $\mathrm{ml} / \mathrm{min}$. en un rango de $330-360 \mathrm{ml} / \mathrm{min}$., en el primer caso, y en el segundo caso fue de $320 \mathrm{ml} / \mathrm{min}$. en un rango de 300-350 ml/min.

- Los Kt/v obtenidos fueron en ambos casos superiores a 1,20 , siendo en el primer caso de 1,42 , en un rango de 1,30-1,69 y en el segundo de 1,45, en un rango de 1,34-1,56.

- La presión venosa osciló entre 150-200 mm Hg. en los dos casos.

- En cuanto al número de infecciones, comprobamos que no hubo mayor incidencia con respecto a otros catéteres tunelizados en otras vías venosas, siendo resueltas en todos los casos con tratamiento intravenoso con vancomicina.

- Los orificios de salida se han comportado, en cuanto a su cicatrización y posterior evolución, como cualquier otro catéter permanente.

- Ambos pacientes han manifestado sentirse cómodos durante las sesiones de HD; de hecho pasan durmiendo la mayor parte de ellas.

\section{Discusión}

Desde hace algunos años, venimos observando cómo la edad de los pacientes que inician un programa de $H D$, es cada vez más avanzada. Esto supone que los accesos vasculares de primera opción, es decir, las fístulas arteriovenosas, sean cada vez más difíciles de conseguir, por lo que estamos asistiendo a un aumento considerable de implantación de catéteres venosos permanentes.

Cuando a nuestra unidad de HD Ilegaron los pacientes con catéter permanente colocado en vena cava inferior, conocedores de que era la última opción de poder realizar tratamiento sustitutivo renal, tuvimos "miedo"; miedo de que algunas de nuestras actuaciones no fueran las más adecuadas para su conservación y duración ya que: la sutura inicial en el catéter tipo Perm-cath la mantuvimos más tiempo del habitual, lo cual supuso casi un perjuicio, ya que hizo una reacción a cuerpo extraño, que más tarde conseguimos subsanar retirando la sutura, sin ocasionarnos mayores complicaciones. También, en nuestro afán de cuidarlo al máximo, probamos distintos tipos 
de apósitos; que fuimos desechando, porque al final resultó que, actuando con el mismo que utilizamos para el resto de los catéteres, conseguíamos mejores resultados.

Nos gustaría que nuestra experiencia sirviera para atenuar el "miedo" o "respeto" que otros profesionales pudieran sentir si se encuentran en una situación semejante a la nuestra, eso sí, sin olvidar nunca extremar los cuidados de enfermería para los catéteres venosos permanentes.

\section{Conclusiones}

- Hemos comprobado que el acceso vascular a través de la vena cava inferior es una opción válida para conseguir una HD adecuada.

- No hemos encontrado mayor número de complicaciones que en otros catéteres tunelizados.

- No implica mayores cargas de trabajo para enfermería, puesto que se aplica el mismo protocolo que para el resto de catéteres venosos permanentes.

- Respecto a la confortabilidad del paciente, ellos mismos nos confirmaron no tener problemas durante la sesión de HD, incluso manifestaron sentirse más cómodos en su vida cotidiana que con los catéteres anteriores.

\section{Agradecimientos}

A los pacientes por su consentimiento y buena disposición para la realización de este estudio. Nuestro especial agradecimiento al Dr. Hermógenes Calero, radiólogo intervencionista de nuestro hospital, autor de la implantación de estos catéteres, por su entusiasmo, disposición e inestimable ayuda en la realización de este trabajo. Al Dr. A. De Paula, nefrólogo encargado de la unidad de HD, por su apoyo y colaboración y al personal del servicio de Nefrología por su ayuda.

\section{Bibliografía}

1. Lung GB, Trerotola S0, Scheel PJ Jr. Percutaneous translumbar inferior vena cava cannulation for hemodialysis. Am J Kidney Dis 1995. 25(5), 732737.

2. Gupta A, Karak PK, Saddekni S. Translumbar inferior vena cava catheter for long-term hemodialysis. J Am Soc Nephro 1995; 5(12): 2094-7.

3. Rajan DK, Croteau DL, Sturza SG, Harvill ML, Mehall CJ. Translumbar Placement of Inferior Vena Cava Catheters: A Solution for Challenging Hemodialysis Access. Radiographics 1998; 18 (5)1155-67.

4. Guías de acceso vascular en Hemodiálisis. Nefrología 2005; 25 (sup.1):1-174. 